\title{
Hacia una búsqueda de metodologías de Cuerpos Expresivos en la educación
}

Recibido: 27 de marzo 2017

Revisado: 31 de mayo 2017

Aprobado: 27 de junio 2017

Flor María Jiménez Bolaños

Costarricense. Directora Centro Educativo Shkénuk y

Casa de Niños San Lorenzo

Montessori. Profesora de

Estado, socióloga, guía Montessori y egresada de la

Maestría en Gestión

Educativa con énfasis en

Liderazgo de la Universidad

Nacional de Costa Rica.

Desde hace 20 años, dirige

espacios para la reflexión

del papel de la educación en

el desarrollo integral de la

niñez

Correo electrónico:

flormaria04@gmail.com

\section{Vanessa De La O Jiménez \\ Costarricense.}

Coordinadora de Arte y

profesora de danza del

Centro Educativo Shkénuk

desde el 2001 hasta el

2016. Bailarina, antropóloga y profesora de danza;

trabaja como profesora de danza y de expresión

corporal con niños y niñas

desde hace más de 15 años.

Actualmente codirige las Jornadas de Reflexión del

Cuerpo y las Corporalidades

en Costa Rica. Cursa el

posgrado en Tendencias

Contemporáneas de la

Danza en la UNA, Buenos

Aires, Argentina.

Correo electrónico:

delaojimenez@yahoo.com
Resumen: Las instituciones educativas tradicionales están construidas dentro de parámetros positivistas y su función es conservar y perpetuar el sistema. Dentro del pensamiento positivista, las palabras cuerpo-mente son una dualidad opuesta y excluyente. La Nueva Escuela de finales del siglo XIX aporta ideas alternativas a la educación institucional tradicional que se encuentra aún vigente y, en este sentido, desde el pensamiento de Ellen Key y María Montessori, se abren nuevas posibilidades para percibir el cuerpo en la escuela. Por último, se expone la experiencia metodológica de la comunidad educativa del Centro Educativo Shkénuk respecto a la integración de los conceptos mente-cuerpo en la escuela, a fin de compartir una visión del ser humano como un ser integral y expresivo.

Palabras clave: cuerpo; corporalidad; educación; cuerpo expresivo; comunidad educativa; educación artística

\section{Searching for Expressive-Body methodology in education}

Abstract: Traditional educational institutions are built on positivist paradigms whose objective is to maintain and perpetuate the system. A positivist approach suggests that the words body-mind are opposite and exclusive dualities. The so called New School of the XIX century provides an alternative to this traditional system of education which is still in use at institutions. The thinking and work of Ellen Key and María Montessori provide a new approach for the perception of the body at schools. Additionally, we present the methodological approach employed by the educational community at Centro Educativo Shekénuk. The educational community at this school assimilates the concept of body-mind with the purpose of sharing a vision of humans as wholistic and artistic beings.

Key words: body; embodiment; education; expressive body; school community; artistic school 


\section{Introducción}

El interés por documentar la vivencia y experiencia recorridas en el Centro Educativo Shkénuk desde sus inicios en el 2000 hasta hoy día nace de la necesidad de teorizar esta práctica. Sin pretender proponerlo como un producto acabado, ha sido un ejercicio necesario para organizar y compartir las aperturas/rupturas que se han llevado a cabo y que se considera han aportado a la educación de los niños y niñas que han pasado por la institución. Además es una forma de evidenciar que los cambios metodológicos y curriculares no solo son necesarios sino posibles, y que aportan una riqueza de posibilidades a las nuevas formas de percibir y participar activamente en una educación pertinente.

El Centro Educativo Shkénuk es un proyecto que se inició gracias a la inquietud, a la investigación y a la experimentación de tres educadoras con una larga trayectoria en el campo de la enseñanza preescolar Montessori - Flor Jiménez, Emilce Ramírez y Lilliana Camacho- y del interés e impulso de un grupo de familias interesadas en una alternativa a la propuesta educativa vigente en ese momento, que fuera capaz de transformarse desde las necesidades y condiciones que enfrenta la niñez del siglo XXI.

Como ya se tenía la experiencia del Método Montessori en preescolar, había una claridad de que la propuesta espacio-temporal de Montessori daba resultados interesantes en el sentido de gestión y administración del cuerpo en el espacio pedagógico que valía la pena rescatar.

Con base en estas discusiones, se encontraron algunos objetivos claros: partir de la organización espacio-temporal y multiedad del Método Montessori, implementar el trabajo interdisciplinario al interior de la comunidad educativa e incluir la educación artística como eje fundamental de la vivencia pedagógica. Y así se inicia esta aventura, con aciertos y desacuerdos, construcciones y deconstrucciones $y$, sustancialmente, con un permanente proceso de cuestionamiento y de cambio, probando los "cómo", con el propósito de crear ese espacio integrador que se está proponiendo.

Desde el inicio, el Shkénuk se rige curricularmente por los programas oficiales del Ministerio de Educación Pública de Costa Rica, que ofrecen una opción valiosa. Un objetivo a mediano plazo es optar por la institución clase B que son instituciones con apertura curricular para lograr oficializar esta propuesta educativa.

Los desafíos que han surgido desde el comienzo se resumen en tres aspectos fundamentales: 1. Trámites de acreditación, 2. Capacitación profesional - 
de docentes y administrativos/as, los/as cuales muchas veces no están habilitados/as para las rupturas- y 3. Las familias -que si bien impulsaron en un principio la gestión de este proyecto, muchas veces también dudan si los contenidos son "suficientes" y cuestionan cómo los/as estudiantes van a enfrentarse e insertarse en el Tercer Ciclo de Educación Diversificada- .

El experimentar asume un "riesgo" que muchas veces crea desconcierto, el cambio implica desapropiarse de las certezas constantemente y esto crea una comprensible tensión y resistencia, y uno de los principales retos ha sido la confianza y credibilidad en este sentido: transmitir con convicción que nuevas propuestas son urgentes pero que sobre todo hay que experimentar su ejecución.

El contacto desde el 2014 con investigadores/as del cuerpo y las corporalidades en América Latina, ha inspirado y acompañado la conceptualización y sistematización de la metodología implementada hasta el momento, ya que muchas de las preguntas planteadas por este movimiento de estudios sobre el cuerpo, tienen que ver con el papel que tiene la educación tradicional en la percepción del cuerpo y por lo tanto, en la construcción de los imaginarios de corporalidad; además cuestionan los procesos racionales como únicos creadores de conocimiento. Muchos de estos cuestionamientos se estaban llevando a cabo desde hacía 14 años en Shkénuk, específicamente: ¿Cómo incluir la experiencia corporal y espiritual en el proceso de aprendizaje y la vivencia en la escuela? ¿Qué otras dimensiones de conocimiento se pueden habilitar en una escuela? ¿Podemos experimentar el autoconocimiento en una instancia educativa?

La primera sistematización metodológica se hizo en el 2015 para las XIII Jornadas Rosarinas de Antropología Socio-cultural, Mesa de Antropología del Cuerpo en Rosario, Argentina y para el II Encuentro Latinoamericano de Investigadores sobre el Cuerpo y Corporalidades en las Culturas, Bogotá, Colombia, ambas en el 2015, que resultó enla ponencia "Shkénuk: Cuerpo y subjetividad en una propuesta metodológica para la educación primaria", que plantea cómo el manejo de lo corporal en la escuela influye en la construcción de las subjetividades. En el 2016 y 2017, parte del personal del Centro Educativo se involucró también en la organización de las I y II Jornadas de Reflexión del Cuerpo y las Corporalidades en Costa Rica.

Para fines de este artículo, se retoma la importancia de la construcción del imaginario corporal en el espacio-tiempo la escuela y de la apertura curricular.

El primer punto contextualiza sobre la visión del cuerpo en la escuela tradicional que separa la relación cuerpo-mente, llevando la mente a un lugar privilegiado para cumplir con los objetivos de la modernidad.

Luego se hace referencia a la contrapropuesta de la médica italiana María Montessori que, desde lo filosófico y metodológico, desafía la práctica corporal de las escuelas tradicionales de principios del siglo XX. Se visibilizan tres aspectos básicos en este sentido: 1. La observación aplicada a los espacios 
educativos, 2. Visibilización de la vida síquica del niño y la niña, y 3. El cuestionamiento del castigo físico.

Por último, abordaremos específicamente la metodología experimentada en el Centro Educativo Shkénuk con respecto a dos rupturas: 1. Tiempo-espacio, y 2. Currículo, aspectos que se considera inciden directamente en la apertura de una educación que permite además del campo racional, permear otros campos y escenarios como el expresivo, sensorial, lúdico, relacional y artístico.

Las reflexiones finales, a manera de conclusión, tienen que ver con el recorrido transitado de las propuestas alternativas de la educación y con el trabajo colaborativo, indispensable en esta labor, además de retomar el concepto "Cuerpo Expresivo" como camino que facilita el autoconocimiento, fin indispensable de la educación dentro de esta propuesta educativa.

\section{Aspectos simbólicos del cuerpo en la escuela}

La dualidad mente-cuerpo es una forma de pensamiento que proviene de una de las ideas planteadas por el filósofo René Descartes y que la modernidad, desde el siglo XVIII, ha tomado como verdad absoluta. Esto le ha dado un lugar privilegiado a la razón y a la mente, como elementos fundantes de todo lo existente, y contrapone el cuerpo como una instancia a la que hay que dominar y silenciar. Con respecto a esto, Penchasnky $(2009,25)$ señala que "el cuerpo y los sentidos van a ser fuente de engaño frente a la mente, el pensamiento, la razón, por lo tanto despreciados en relación al conocimiento". Era el siglo de la ciencia, del método científico y de la racionalidad.

La escuela tradicional, como la conocemos hoy en día, tiene sus fundamentos en ese pensamiento racional; además, fue concebida para unificar y universalizar el conocimiento. Sin duda, la escuela ha jugado un papel importante en la formación de la "civilización" propuesta en la modernidad y su universalización ha sido un triunfo para los derechos humanos y para la alfabetización, que ha permitido a la mayor parte de las poblaciones el acceso e inserción dentro del mercado laboral, sin embargo Puiggrós $(2016,39)$ plantea que "la apropiación de conceptos tales como progreso, civilización, libertad y democracia, [establecen] un sistema de oposiciones con categorías que descalifican a los sujetos oprimidos latinoamericanos y a las prácticas y sentidos por ellos producidos". Es decir, todos estos conceptos llegaron a las escuelas por imposición y como una forma de "universalizar" la civilización, sin tomar en cuenta los contextos, realidades y saberes a donde llegaba esta nueva forma de colonización. La escuela era una institución fundamental para reproducir y perpetuar esta idea de civilización universal que implantaba el sistema hegemónico occidental, dejando de lado las riquezas y conocimientos locales, que no forman parte de los currículos. 
En este proceso quedaron excluidos dos aspectos fundamentales: el conocimiento que se puede crear a través del cuerpo y las corporalidades y la invisibilización de ciertos contenidos propios y locales de las diferentes culturas.

El cuerpo en este contexto parece que está olvidado sin embargo está recibiendo información muy clara de domesticación. Pateti (2017) señala que "la aprehensión de los conocimientos pasa por la apropiación de las posibilidades corporales, que así como las abstracciones de tiempo y espacio deben ser elaboradas primero en el lienzo corporal". Es decir, el aprendizaje lo elaboramos también corporalmente, incluso si estamos dando una mayor preponderancia a lo racional. La racionalización no existe sin un cuerpo que esté presente y viceversa, cuando el cuerpo se mueve está pensando, está creando conocimiento desde esa experiencia y su incidencia se manifiesta tanto a nivel ideológico como a nivel motriz. Por lo tanto, desde ésta propuesta es indispensable la observación del uso que se ha dado al cuerpo en la historia de la educación para poder comprender sus mecanismos y sobre todo para crear estrategias que ayuden a cuestionar lo impuesto.

Desde lo ideológico,

Las representaciones y saberes acerca del cuerpo son atributos de un estado social, de una visión del mundo y, dentro de esta última, de definición de la persona. El cuerpo es una construcción simbólica, no una realidad en sí misma" (Le Breton 2012, 13).

El imaginario corporal es una construcción directamente relacionada con el contexto sociocultural e influye en la percepción de la persona y del mundo. Desde este punto de vista, si la corporalidad en la escuela obliga al estudiantado a permanecer inmóviles, en quietud y uniformes, e incluso reprime y disciplina sus impulsos corporales naturales, la construcción simbólica y la relación que se crea entre el cuerpo y la persona es distante y de dominación: la mente domina los instintos del cuerpo, se debe llegar a ser algo que no somos. Este aspecto también tiene implicaciones en el nivel motriz:

La mecanización, rigidez e insensibilización corporal y de la correspondiente desestructuración mental, lo que puede manifestarse por una personalidad inhibida, sujeta a moldes y estereotipos de comportamiento; una imagen corporal pobre, un desconocimiento del propio cuerpo y una desorganización del movimiento (Vallejo 2001, 17). 
1.https://cambiemoslaeducacio n.wordpress.com/2015/04/08/la -escuela-tradicional-estacolapsando-entrevista-anoemi-paymal-antropologa/
En una entrevista realizada a la antropóloga Noemi Paymal y publicada el 8 de abril del 2015 por el blog de la página web Cambiemos el mundo, cambiemos la educación, ella menciona que un ejemplo para una pedagogía holística, que entienda y atienda las necesidades de los niños y de los jóvenes de hoy debe:

Empezar por recuperar todos los niveles de desarrollo del cuerpo. El niño tiene que moverse cada 20 minutos en primaria y si es más pequeño tiene que hacerlo todo el tiempo. Decirles que no se muevan es como decirle a la planta que no crezca o al sol que se pare. Es su naturaleza y hay que anclar el conocimiento con el movimiento (Paymal, 2015) ${ }^{1}$.

El ser humano es complejo, total, interdependiente, emocional, espiritual, mental e integrado con él mismo y con los demás, y su cuerpo es la materia desde la que vive esta experiencia. Si el ser humano es su cuerpo, también tiene la posibilidad de ser expresión, generador de ideas, pensamientos, emociones, creador de posibilidades... Así como puede reprimirse puede liberarse, pero para eso es necesario, primero,

Entender al cuerpo como el producto de un conjunto de sistemas simbólicos socialmente compartidos y atravesado por significaciones que constituyen la base de su existencia individual y colectiva, el modo de estudiar el cuerpo es observar el lugar que este ocupa en el fenómeno que se ha seleccionado (Mora, 2010).

Desde ese cuerpo al que le sucede la vida en todas sus dimensiones, es desde donde el ser humano se cultiva, aprende, se conoce y se conecta consigo mismo/a y con su entorno. El cuerpo es el territorio, el lugar desde donde se vive, total y plenamente, y desde el cual se experimenta y se relaciona con otros cuerpos y con el mundo.

\section{La Nueva Escuela}

Los llamados movimientos de la Nueva Escuela surgen a finales del siglo XIX, como propuesta alternativa a la educación oficial, y cuestionan la homogenización por medio del "adiestramiento". Además, plantean que niños y niñas tengan una experiencia libre, integral y humanista en la escuela, que se 
abra el espacio a la diversidad, tomando en cuenta el contexto y atendiendo las particularidades y las necesidades específicas de cada alumno/a.

Los aportes de Ellen Key (1849-1926) y María Montessori (1870-1952), dentro de este movimiento de la Nueva Escuela, han inspirado distintas propuestas educativas no solo en lo pedagógico e ideológico, sino también en lo político respecto de la apertura de espacios desde la igualdad de género. Fueron feministas y lucharon por sus derechos como mujeres pensadoras, autodidactas y, sobre todo, reformadoras y visionarias, con aportes que, luego, fueron tomados en cuenta en los derechos humanos y de la niñez.

En el artículo "Ellen Key(1849-1926)", publicado por la Unesco, Thorbjörn Lengborn (2001) señala que Ellen Key consideró el siglo XX como "El siglo de los niños" y postuló la importancia de la libertad personal y del desarrollo independiente desde las individualidades de la niñez. Además, en sus obras Belleza para todos (1899) y Educación popular con especial consideración al sentido estético (1906) visibiliza la belleza y el arte como una forma de elevación moral y de educación por la humanidad.

María Montessori fue la primera mujer médica que se graduó en Italia. Dentro de su práctica profesional, asistió a centros de niños y de niñas con retardo mental y se interesó en mejorar sus condiciones. Observó que un ambiente escolar estimulante y adecuado a las necesidades de desarrollo de los/as infantes favorecía el aprendizaje de forma natural. Se interesó por la educación de los niños y de las niñas desde edades tempranas y, a través de la observación rigurosa de su actividad e interés, escribió El método de la pedagogía científica (1909).

Foto 1. María Montessori con sus alumnos en el Colegio La Anunciación, 1939

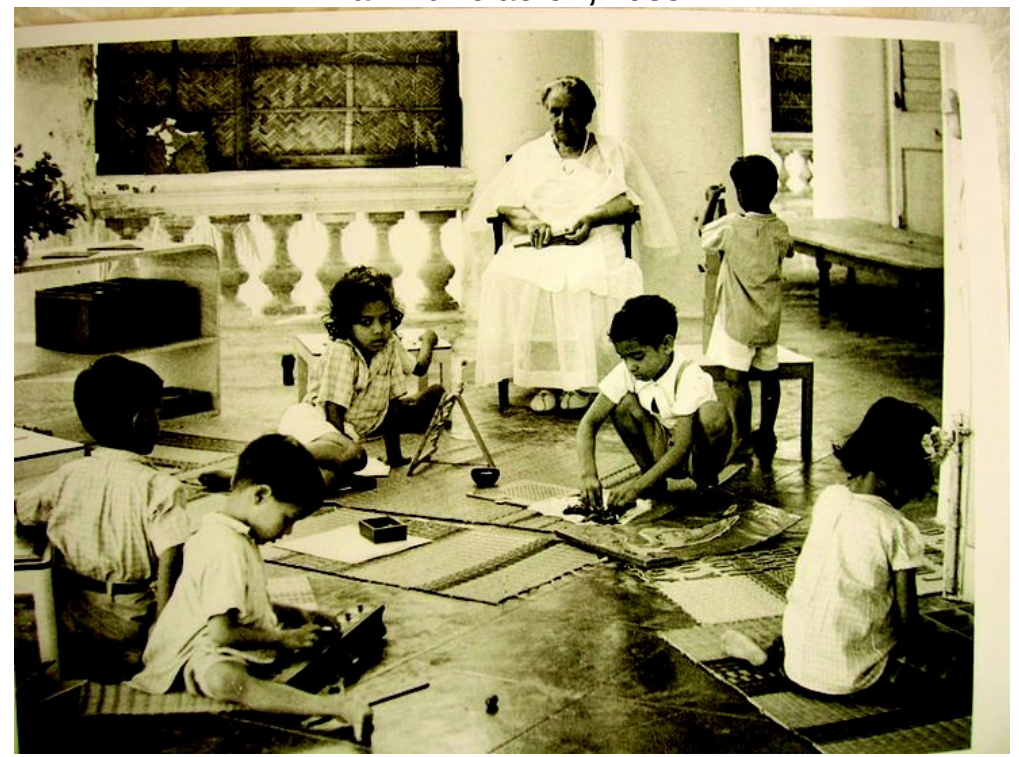

Fuente: Nachiappan. 
Montessori ha sido catalogada, dentro de la Nueva Escuela pedagógica como naturalista biologista, ya que pensaba que la nueva educación debía construirse basándose en las leyes de la naturaleza y no en ideas preconcebidas o prejuicios, según lo indican Pineau, Dussel y Carusso $(2013,112)$, para Montessori, "la naturaleza del niño es el centro de currículo". Y por esta razón, se dedicó a observar la naturaleza de la niñez y, con base en su observación, planteó su método.

Para esta pedagoga:

El primer ambiente es el mundo, y los otros ambientes, como la familia y la escuela, deberán satisfacer esos impulsos creadores que tienden, bajo la guía de las leyes cósmicas, a realizar el perfeccionamiento humano. Cuando sean dominados los prejuicios por el conocimiento, entonces aparecerá en el mundo el niño superior con sus poderes maravillosos que hoy siguen ocultos; entonces aparecerá el niño que está destinado a formar una humanidad capaz de comprender y controlar la actual civilización (Montessori 1986, 111).

Con el concepto niño superior, Montessori se refiere al potencial de los infantes por encontrarse consigo mismo; por descubrir su propia manera de aprender y de ver el mundo sin una realidad impuesta desde afuera; no obstante, para que esto suceda, el ambiente debe estar preparado, con las condiciones que despierten esa curiosidad y concentración.

A pesar de que las rupturas de María Montessori en el campo de la educación y de la pedagogía son numerosas, para fines de este artículo, se han visibilizado tres aspectos fundamentales en el nivel ideológico y simbólico en cuanto a la ruptura de los cuerpos en el pensamiento racionalista dualista:

\section{La observación}

El trabajo literario y pedagógico de Montessori está escrito a partir de observaciones exhaustivas a niños y a niñas, primero, en Italia; y luego de su exilio, en la India. La observación fue su herramienta metodológica para la elaboración del cuerpo pedagógico de su obra y a partir de donde escribió el libro el Método de la pedagogía científica (1909). Si bien el Método Científico busca crear generalización, una de sus generalizaciones fue que cada niño y niña tiene, no solo su manera, sino su tiempo para aprender, dentro de periodos sensibles y que se interesan naturalmente por el aprendizaje si en el ambiente están las herramientas (materiales) adecuadas. 
También, observó que, en ese "ambiente preparado", el grupo de niños desarrolla sus necesidades no solo intelectuales sino también psíquicas, de físicas y emocionales; y que los seres humanos aprendemos en movimiento, es decir, que el movimiento libre de los cuerpos en el espacio genera poder de decisión y gestión y el manejo del tiempo de una forma individualizada.

Montessori invitó a recibir de los niños y niñas información, a percibir, a escuchar, a observar, a intuir y experimentar a través de los "laboratorios" de clases, y constatar cómo eligen y se construyen a sí mismos /as.

La observación se vuelve para ella un elemento fundamental para entender a la otra persona y hace que esta otra persona sea tomada en cuenta. La relación con el otro en el proceso de aprendizaje deja de ser pasiva, ya que el/la otro/a es parte del proceso y participa de forma activa a través de su información corporal y síquica. El método lo diseña con respecto a las particularidades observadas.

\section{Visibilización de la vida síquica en el niño y la niña:}

En cuanto a este aspecto, Montessori plantea que el niño/a no es un recipiente vacío que el adulto tenga que llenar, sino que es un ser que puede crearse a sí mismo/a.

Desde el pensamiento positivista, se creía que los niños y niñas no tenían conocimientos y las personas adultas eran los encargados de introducir y enseñar los conocimientos necesarios para que después de su desarrollo, en la edad adulta éstos pudieran incorporarse a la "civilización", es decir, era el adulto el que permitía que los infantes se fueran transformando en seres activos.

El adulto se presentó a sí mismo como el plasmador del niño y el constructor de su vida síquica (...) el adulto se ha atribuido un poder casi divino: finalmente, piensa que él es el Dios del niño y piensa de sí mismo como Dios al Génesis: "crearé al hombre a mi imagen y semejanza" (Montessori 1982, 70).

Montessori hace este paralelismo refiriéndose a que las personas adultas dirigen la crianza de los niños y niñas y les imponen cómo deben ser, sin respetar su naturaleza individual; utiliza también el término "embrión espiritual" a través del cual abre la posibilidad a la educación y a la pedagogía de ver a los niños y niñas como seres completos desde su nacimiento pero que el ambiente en el que se encuentren será determinante para que este "embrión espiritual" se desarrolle o no. En las palabras de Montessori $(1986,94)$ "se dan desarrollos internos dirigidos por energías creadoras, y estos desarrollos pueden llegar a una madurez antes de manifestarse exteriormente". 
Contrapone la infancia inerte a la infancia psíquica. Es decir, los niños y niñas no tienen por qué repetir una forma estandarizada de ser, ellos/as son capaces de descubrir sus propios intereses y desarrollarlos.

\section{Cuestionamiento del castigo físico}

El castigo físico fue una práctica usual, tanto en los hogares como en instituciones religiosas, educativas y estatales; el hincarse, los azotes, el mantenerse de pie durante largos periodos, entre otros, fueron los modeladores y reguladores no solo de la conducta, sino del movimiento de las personas.

En Occidente, tiene una connotación católica-religiosa, los santos eran santos porque flagelaban su cuerpo, recinto del deseo:

En la cultura cristiano-católica la noción de cuerpo sustenta la de persona, ello significa que la persona se constituye y es reconocida como tal cuando controla su parte sensible y no racional porque el "cuerpo" es entendido como el componente material de lo humano y, en tanto tal, se percibe como un obstáculo para la salvación y perfección del alma (Araya, 2006).

Dentro de las instituciones educativas, esa forma de castigo se practicaba regularmente con la convicción de que, a través de él, el niño o la niña inquieto/a y "malo/a" lograba adquirir el conocimiento deseado y volverse "bueno/a". Sin embargo, en el libro El niño, el secreto de la infancia (1982), Montessori dedica el capítulo "Los derechos del niño" a visibilizar las condiciones de los niños y de las niñas de principios del siglo XX, ya que en esa época no solo eran castigados físicamente por las familias y por las escuelas, sino que muchos trabajaban y llegaban exhaustos a clases en donde eran obligados a estar en una postura corporal de inmovilidad.

En este orden de ideas, algunos infantes presentaban, por malas condiciones higiénicas, enfermedades y una alta mortalidad. Observó, por lo tanto, que muchos de los castigos físicos que se practicaban en las escuelas eran por las condiciones con las que los niños y las niñas llegaban a y que tenían muy poco que ver con su inteligencia o interés por aprender. Denunció la invisibilización de los/as niños/as en la sociedad y defendió su derecho a tener instituciones y personas que los/as defendieran y protegieran.

Luego de observar esas condiciones, Montessori diseñó un espacio pedagógico en el cual el castigo físico no tenía lugar. Para ella, la relación con los niños/as es de amor y de respeto, tanto en sus procesos psíquicos como físicos. La propuesta espacial en la clase, donde los materiales están a disposición y cada niño/a elige, con autonomía, lo que quiere hacer y ponerlo libremente en el espacio, también permitió horizontalizar la relación adulto/a y 
niño/a. Ahora, el adulto/a no es un vigilante de la conducta del niño/a, sino un facilitador/a de su desarrollo.

Montessori desmitificó la inmovilidad y control innecesario del cuerpo; para ella, la libertad de movimiento de los niños/as, en un "ambiente preparado", es fundamental dentro del proceso de aprendizaje y si esto se posibilita, no hay por qué corregir; el aprendizaje surge de manera espontánea.

\section{Propuesta metodológica: ¿cómo abrir el espacio a cuerpos expresivos desde la educación?}

Se hablará, a continuación, de tres rupturas -propuestas metodológicas- que se han practicado en Shkénuk durante 17 años y que han permitido la exploración y la experimentación de la educación de una forma diferente. La palabra shkénuk significa 'amanecer' en bribri, la lengua indígena viva de esta población originaria proveniente del Pacífico y Caribe sur de Costa Rica.

Si bien esas rupturas están inspiradas en la propuesta de Montessori, es importante visibilizar que el trabajo colaborativo de la comunidad educativa ha sido fundamental tanto para contextualizar la experiencia como para permanecer en una búsqueda constante.

\section{Tiempo-espacio}

El desplazamiento libre en el espacio y la inclusión en todas las áreas posibles dentro del salón de clase: vida práctica, sensorial, matemática, lenguaje, áreas culturales (botánica, zoología, biología, música y arte) son las características principales de este rompimiento en el espacio. El salón es un pequeño universo en donde todos los materiales están a disposición y se escoge con cuál establecer una relación o un vínculo de aprendizaje dependiendo de la edad y de las preferencias. Cada ejercicio está diseñado de acuerdo con diferentes necesidades psíquicas, intelectuales, sensoriales, físicas y emocionales.

En este tipo de clase propuesta por Montessori, la apertura al movimiento libre implica apropiarse de la corporalidad mientras aprendemos conceptos y racionalizamos acerca las palabras mente-cuerpo; crea una conciencia espacio-temporal fluida porque cada quien es libre de elegir, de definir y de organizar sobre su tiempo, su espacio y su actividad.

Partiendo de esta propuesta de Montessori, en Shkénuk, hay materiales pedagógicos que se encuentran alrededor del salón de clase en estantes y los niños/as pueden elegir el material con el que trabajaráncada día, así como el lugar donde se sentarán con el material. No hay lugares predeterminados.

Dentro de la clase, hay mesas individuales y colectivas de diferentes formas, tamaños y alturas (redondas, cuadradas, rectangulares) y algunos materiales se usan sobre alfombras en el piso. También, se pueden utilizar espacios al aire libre. Cuando terminan el ejercicio sin que nadie les dé la indicación, se 
ponen de pie y van a dejar el material que estaban utilizando para elegir otro. Asimismo, pueden hacer ejercicios grupales y pueden elegir las materias para trabajar durante el día. Al final del año, deben haber cumplido con un material estándar, pero su elección de gestión del tiempo es clave en esta propuesta de aprendizaje.

Aunque hay tiempos establecidos para recreos y horarios que sirven de base para la organización general, no hay horarios predeterminados por materias porque los trabajos son individualizados la mayor parte del tiempo, es decir, mientras un/a niño/a está trabajando en ejercicios de matemáticas otro/a puede estar en un ejercicio de lenguaje o botánica.

Aquí el concepto de tiempo va ligado al del espacio, es decir, este último provoca una temporalidad en la cual lo más valioso es el proceso y el ritmo de aprendizaje de cada niño/a.

Foto 2. Observamos niños y niñas de I y II Ciclos trabajando en diferentes espacios

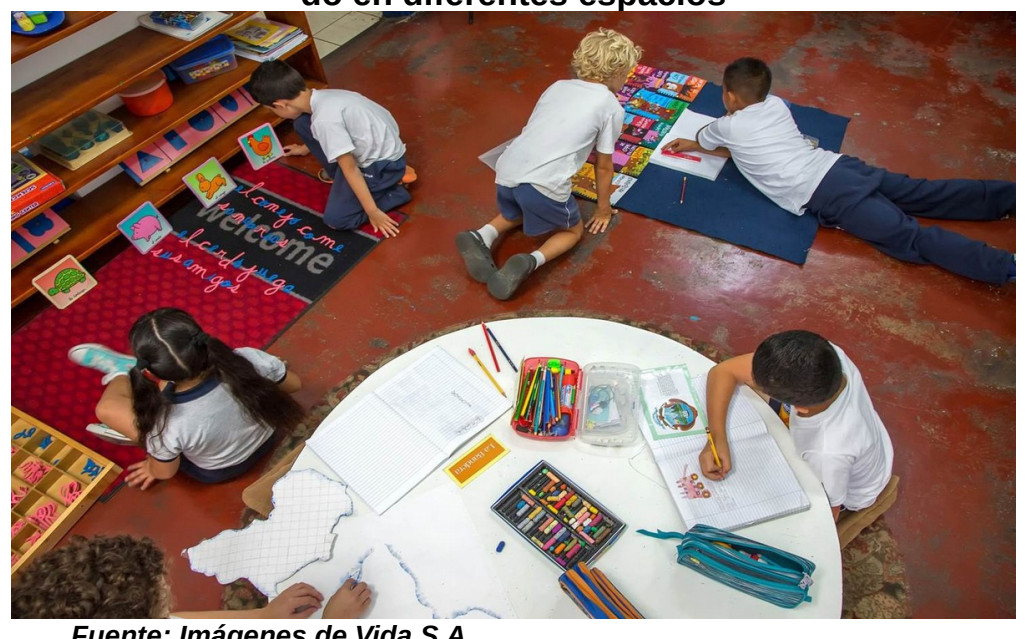

Fuente: Imágenes de Vida S.A.

Dependiendo de la cantidad de alumnos, en cada sala, hay una maestra titular y una o dos asistentes, que juntas organizan y elaboran el material pedagógico que se encuentra en el salón de clase. La observación, la intuición y el estudio exhaustivo de sí mismo/a y de las necesidades de los niños/as son las herramientas fundamentales de las maestras. La maestra debe ser un medio para que los niños y las niñas confíen y aprendan desde sus instintosguías internos.

Los salones de clase están conformados por un rango de edad, que va de 3 a 4 años aproximadamente cada uno: 1. Preescolar: de 3 a 6 años; 2. I ciclo de 6 a 9 años; y 3 . II ciclo de 9 a 12 años. En el espacio multiedad, aflora la diversidad de subjetividades y percepciones, con diferentes niveles de madurez y de respuesta que ayudan a resolver las situaciones cotidianas que los niños y las niñas enfrentan; además, se crea un vínculo escolar natural por- 
que los seres humanos, desde el nacimiento, se relacionan en grupos multiedad (la familia y la sociedad).

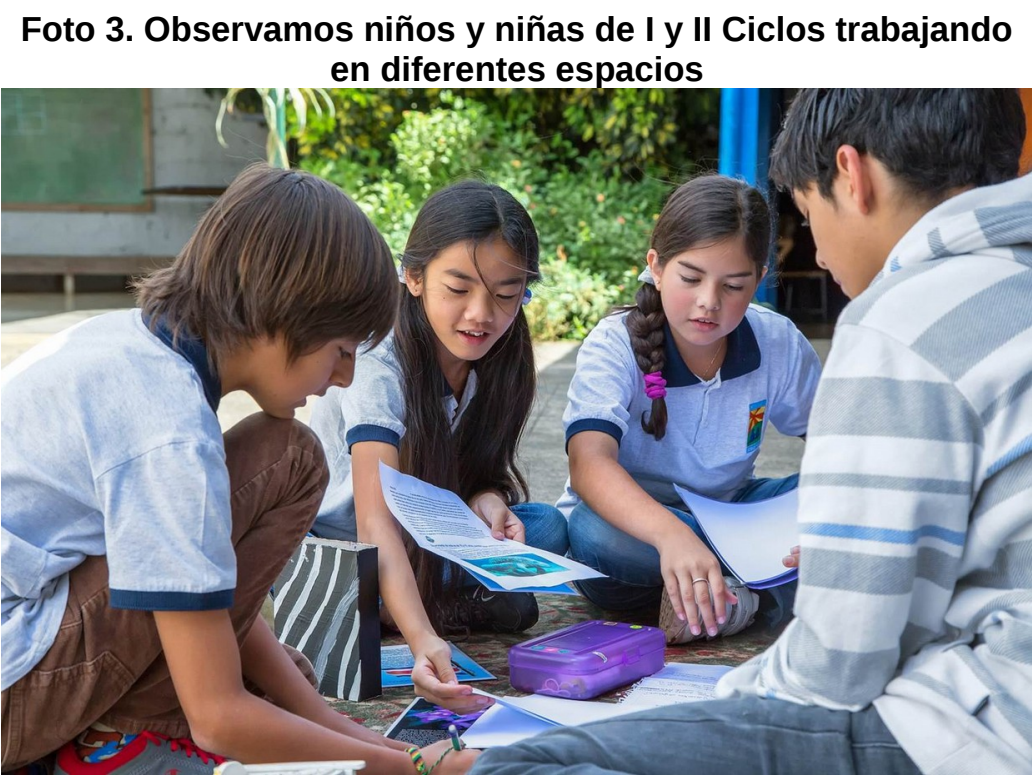

Fuente: Imágenes de Vida S.A.

También, se utiliza el círculo como espacio de diálogo para abordar temas generales, ya sean de contenido o vivenciales. La disposición de la clase en círculo genera horizontalidad, igualdad, confianza, y es un lugar donde aflora una cosmovisión infantil, fresca, real y espontánea porque está la posibilidad de observarse mientras se está conversando.

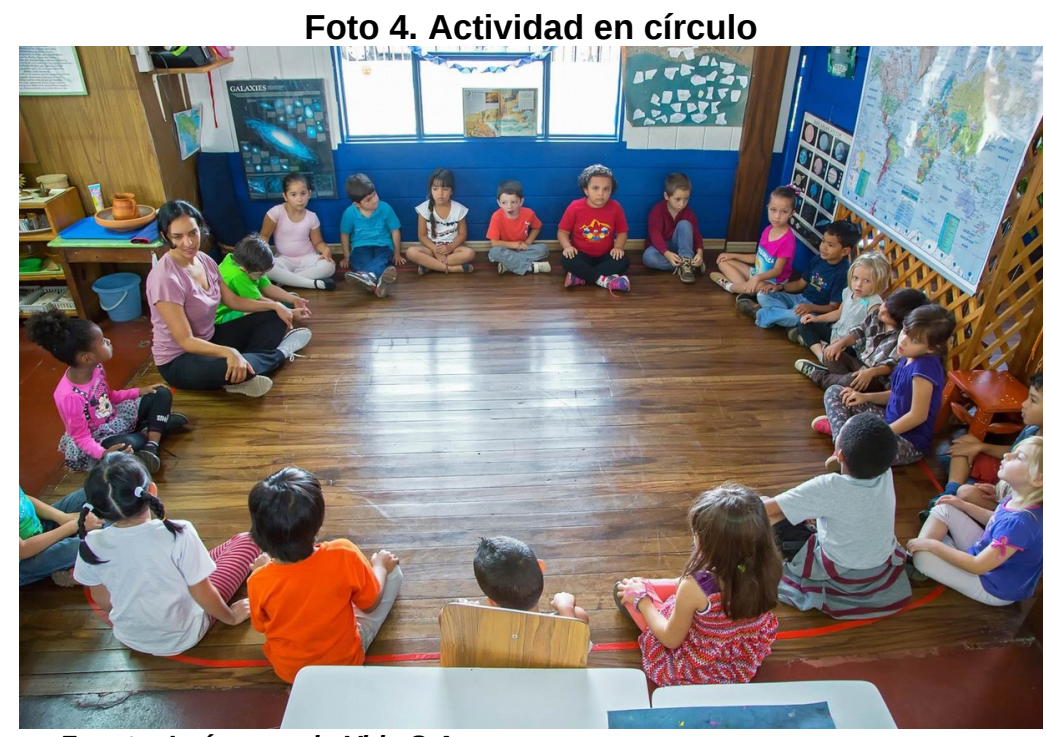

Fuente: Imágenes de Vida S.A. 


\section{Currículo abierto}

Si bien en el Centro Educativo Shkénuk se utilizan los programas del Ministerio de Educación Pública como base, los contenidos no siempre se abordan de manera lineal ni tampoco la organización de las materias que se indica en esos programas se mantiene firmemente. Además de los contenidos que se plantean en este plan de estudios, se propone preguntar a los niños y niñas sobre lo que desean aprender y conversar en la clase; y en esta situación, aparece una gran cantidad de inquietudes y de curiosidades, no solamente intelectuales, sino también emocionales, espirituales, relacionales y artísticas.

Intencionar la apertura de espacios donde las sobras del esfuerzo ordenador dan paso a la imaginación creadora, que rompe y abre espacio hacia los caminos inexplorados, hacia brechas de incertidumbres, caminos donde lo radical se inscribe en la espontaneidad, la experimentación, la vivencia y la autodeterminación (Hurtado 2008, 132).

La temática escolar se vuelve ilimitada y el aporte de las ideas de niños y niñas los/as hace sentirse más involucrados/as e interesados/as. Para el cuerpo docente, también, es una experiencia que plantea una constante reformulación y enriquecimiento de la información, debido a que las inquietudes y las expectativas son extensas. Para López $(2006,220)$, la formación integral "solo se realiza cuando uno sigue un proceso de ajuste a la propia realidad. La realidad humana se desarrolla y llega a la madurez a través del encuentro", es decir, tiene que existir una contextualización, acompañada del diálogo $y$, cuando el espacio se abre a las preguntas, el material se contextualiza.

Cuando se abre el espacio a esta pregunta no solo el estudiantado se interesa, sino también el cuerpo docente se mantiene en constante revisión y cambio de los materiales. Además, se reconoce que el cuerpo docente no es el único que tiene la información o el conocimiento.

Las familias, como parte de la comunidad educativa, también enriquecen la experiencia de aprendizaje a través de charlas y de talleres sobre determinados temas pertinentes. Este es un conocimiento cercano, experiencial que se puede aprovechar. Por ejemplo, en la escuela, se han realizado charlas y talleres con padres y madres de familia de los siguientes temas: fotografía, ingeniería, arqueología, energía, panadería, escultura, entre otros

De los intereses que surgen, se selecciona un gran tema anual que es el hilo conductor del currículo. Los temas anuales son abordados desde muchas perspectivas y, a través de esta práctica, se ha logrado que disciplinas artísticas y académicas permanezcan en constante diálogo, impregnando y am- 
pliando sus perspectivas, por medio de la transversalización de los contenidos.

Esta interdisciplinariedad enriquece y diluye fronteras disciplinares, correlaciona temas y materias y desde múltiples puntos de vista. Algunos de los temas anuales abordados han sido: la paz, las religiones del mundo, los continentes, el agua, la gratitud, los elementos, y este año se está trabajando a partir de biografías de mujeres.

En el 2017, se está abordando el tema biografías de mujeres. Los niños/as iniciaron creando un árbol genealógico de las mujeres de sus familias y han podido observar y reconocer, a través de esta práctica, diferentes esencias y formas de ver el mundo. Han podido resignificar la mirada hacia la participación de las mujeres en sus familias, desde lo más cotidiano hasta grandes aportes en los niveles científico, educativo, deportivo y artístico.

Después de desarrollar ese tema, se abordarán los diferentes tópicos del currículo desde la mirada, estudio o aportes de mujeres, tanto en Costa Rica como en el ámbito internacional, por ejemplo: Wangari, desde el arte; Isadora Duncan, desde la danza; Yolanda Oreamuno, Carmen Lyra y Carmen Naranjo, desde la literatura.

La inclusión de actividades artísticas no como relleno curricular sino como eje fundamental del currículo convierte al arte, según Lowenfeld, $(1973,8)$, en una "válvula reguladora entre su intelecto y sus emociones. Puede convertirse en el amigo al cual se retorna naturalmente cada vez que algo nos molesta -aun inconscientemente- el amigo al que se dirigirán cuando las palabras resultan inadecuadas".

El "Cuerpo Expresivo" es una propuesta de investigación generada en la propia institución pensada y planteada desde la exploración artística y/o corporal, lo que abre la posibilidad para conocer, sensibilizar y explorar el cuerpo. De las preguntas metodológicas fundamentales que se han planteado en Shkénuk en los últimos 5 años están: ¿Cómo legitimar curricularmente el cuerpo para reivindicar a través de él, el fortalecimiento de habilidades sociales, afectivas, emocionales y de conocimiento que le son intrínsecas? ¿Cómo incluir al cuerpo no solo como contenido si no dentro del proceso de aprendizaje, con igual importancia que el componente mental o académico y plantear cuál es la relación entre todas esas dicotomías?, ¿qué hay en el medio? ¿Cómo se siente el cuerpo en el espacio de aprendizaje en la escuela? ¿Qué hay que hacer para que tenga un espacio para manifestarse? ¿Cómo crear los espacios para la manifestación corporal plena e integral? ¿Cómo integrar la práctica corporal en cada espacio de la comunidad educativa?

Con el recurso artístico, y a través del cuerpo, se logra conjugar y terminar de dar espacio a muchas más posibilidades de experimentación, expresión y sensibilización, potenciando la capacidad comunicativa-expresiva y creativa en los niños y niñas porque por medio de él pueden decir y expresar situaciones y vivencias que no se pueden verbalizar. 
Cada niño y niña tienen la posibilidad de escoger un instrumento (flauta, piano, guitarra, percusión), y además reciben clases regulares de música, canto, danza, teatro y artes plásticas; también se imparten talleres ocasionales de capoeira, yoga, parkour, literatura, clown, entre otros, con el objetivo de que los/as alumnos/as tengan una apertura a las posibilidades de conocimiento y expresión que existen y decidir con cuál o cuáles de estas se sienten identificados/as o les representan un reto.

El gran tema anual es el eje conductor del festival artístico. Este tema es tratado desde diferentes perspectivas por los/las docentes, lo que permite que en las materias artísticas, el estudiantado llegue con un bagaje que enriquece el aporte creativo y la improvisación en estas clases. El cuerpo docente se convierte en editor y guía. Por ejemplo, durante el 2016, se trabajó el tema de los elementos y cada estudiante escogió el que quería representar; en la clase de danza, se trabajó en el guion dramático y en los movimientos que se llevaron al montaje; en la clase de música, en la creación sonora de cada elemento; en la case de arte, en el diseño y en la realización de uno de los vestuarios.

Foto 5. Festival artístico 2015, sobre la temática de los continentes

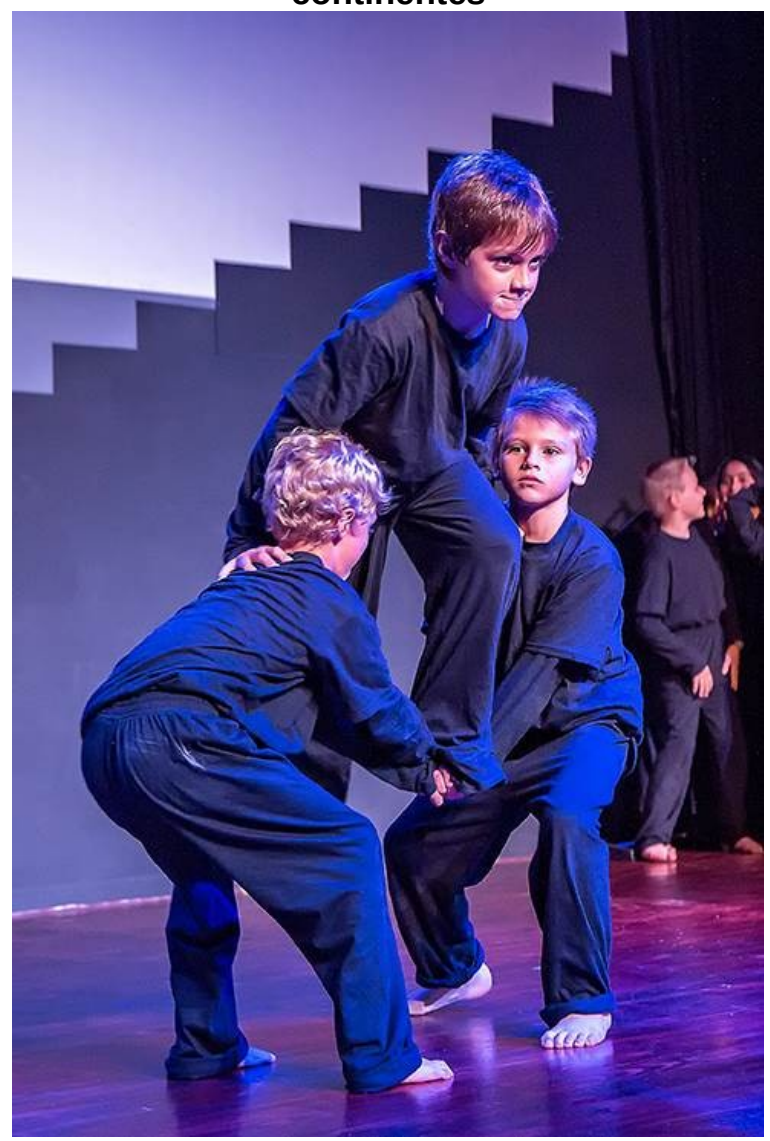

Fuente: Imágenes de Vida S.A. 
La educación artística es indispensable pensarla como un elemento que aporta disciplina, concentración y el deseo de autosuperación; sin embargo, el aspecto disciplinar debe de estar también acompañado de sensibilización, expresión y liberación de inquietudes.

Foto 6. Festival artístico 2016, sobre la temática de los continentes

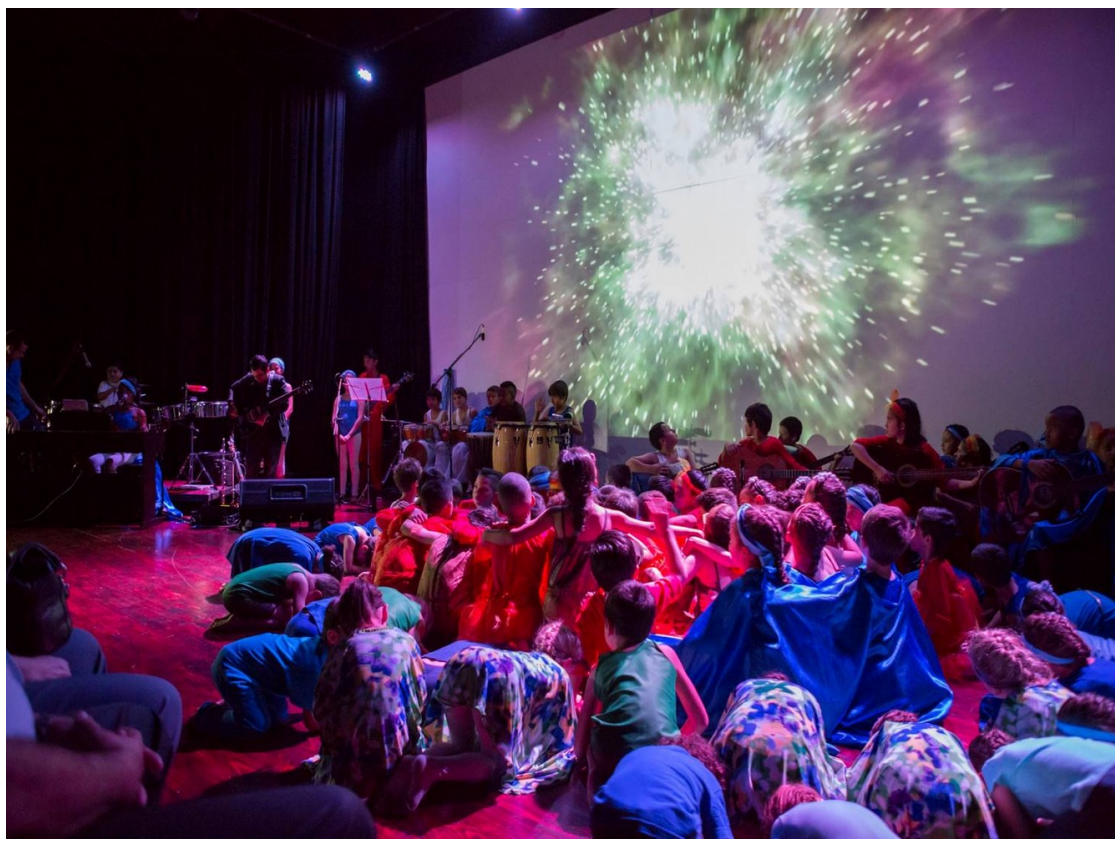

Fuente: Imágenes de Vida S.A.

\section{Reflexiones finales}

Como reflexiones finales y a partir de la contraposición del pensamiento hegemónico con las teorías de la Nueva Escuela y la experiencia vivida dentro de una comunidad educativa Shkénuk, interesa reflexionar en los siguientes sentidos:

- Los sistemas educativos, a pesar de sus esfuerzos, no siempre son racionalistas puros. Paralelo a los pensamientos hegemónicos, han surgido pensamientos e ideas que poco a poco se filtran y operan como micropolíticas. Si bien el pensamiento racional impregnó los sistemas pedagógicos y educativos en Occidente y estos llegaron a América Latina también como una forma de colonización, imponiendo homogenización, también se encuentran caminos para resistir. Las particularidades culturales surgen mayor o menormente en los sistemas educativos porque el ser humano está en constante movimiento, es inquieto/a, no solo corporal sino también psíquicamente. Consciente o inconscientemente, con claridad o sin claridad, el ser humano necesita elevar su nivel de conciencia y el surgimiento del pensamiento 
crítico de vanguardia; contrapuesto a la oficialidad que surge, es muy interesante e indispensable de indagar.

- Los dualismos y los currículos en las escuelas se han influenciado, desde finales del siglo $X X$, de alternativas que promueven la necesidad de temáticas contextualizadas, abiertas e integrales, incluso en las escuelas más tradicionales, porque el resultado es el interés e involucramiento más activo del estudiantadoen clases. En este sentido, siguen surgiendo sistemas de educación que intentan acercarse a la visión de la educación como una experiencia de vida holística y de autoconocimiento, con muy buenos resultados y que sirven de inspiración para otros movimientos. Siguen creándose nuevas rupturas.

- Los importantes aportes de mujeres de finales del siglo XIX, en el pensamiento pedagógico de la Nueva Escuela son invaluables y su incidencia política se está empezando a observar de forma más ponderada en el siglo XXI. Este pensamiento no siempre se ha interpretado de la mejor manera y tiene aspectos que podemos cuestionar; sin embargo, su mayor importancia radica en la visibilización de los derechos de la niñez y la apertura de ver a los niños/as como seres completos y diversos/as, con sus particularidades e individualidades, y que el rol que juega el cuerpo dentro de la escuela determina patrones impuestos y, por lo tanto, impide la libre expresión de las subjetividades.

- Las luchas de resistencia contra el sistema hegemónico son colectivas; el diálogo y la reflexión, entre los miembros de las comunidades educativas, así como la apertura de espacios de discusión sobre educación en el ámbito social, son muy importantes:

Nadie, sea cual sea la corporalidad que encarne, es realmente autosuficiente. Por esto pienso en luchas cómplices y afines. Busco potencias vinculadas y vinculantes. Creo que es necesario y vital encontrarse. Será el encuentro, el lugar de la potencia, el lugar desde donde partir, el lugar de la posibilidad. (Masón, 2014).

Las observaciones y la implementación metodológica en la educación alternativa deben mantenerse en una transformación, asimilación y adaptación constantes que posibiliten la confrontación y el diálogo de la teoría con la práctica. La educación es un proceso colectivo y continuo, una espiral de cuestionamiento, revisión, conversación, discusión, verificación incesante y, por eso mismo, son tan necesarios los espacios de reflexión.

- Las metodologías mencionadas en este artículo, en general, relacionan, desde la experiencia, los conceptos mente-cuerpo, y acercan el 
espacio de comprensión y de relación entre sí. Abrir el espacio y el tiempo al movimiento, así como al currículo les permite a los niños/as desarrollar la escucha y el conocimiento de su propio cuerpo.

Por su parte, se ha observado el mejoramiento en la autoestima de quienes han experimentado la sensación de poseer un cuerpo único que disfrutan, cuyos límites pueden ser administrados por ellos mismos; además, este método ha provocado mejoras sustanciales en niños y niñas con diversos problemas emocionales (timidez, agresividad, ansiedad, competitividad, pasividad, autismo, asperger) y de aprendizaje (dislexia, déficit atencional); ha permitido la integración paulatina del concepto de proceso contrapuesto al valor de la inmediatez que prevalece en la sociedad actual; ha ampliado los lapsos de concentración de los niños y de las niñas que han experimentado la sensación de sobrepasar sus propios límites, y ha creado una conciencia de que las acciones individuales añaden un ingrediente significativo en el nivel de respuesta grupal, y sobre todo, ha permitido que los niños y las niñas se den cuenta de que son capaces al conectarse con sus debilidades, habilidades y destrezas.

- Desde las propuestas emancipadoras, se debe revisar la posición y el papel que tiene el cuerpo. Hay poca conciencia de que el cuerpo es inminentemente inseparable del raciocinio; sin embargo, a través de la práctica corporal, se enriquece la noción del yo, la idea que tenemos de nosotros/as mismos/as y la relación con los demás. Habitar el cuerpo y estar consciente de ese habitar posibilita la apropiación de un territorio, lleno de ideas, creatividad, expresión y posibilidades y es un arma muy poderosa para el autoconocimiento y el camino a la libertad. Pese a ello,

El empeño de la teoría social por fijarse en el cuerpo,

pueden tener las propias limitaciones de la/s cultura/s corporal/es hegemónica/s occidental/es, y revisar, por lo tanto los etnocentrismos inherentes a esta teoría social recuperando y aprendiendo de lecturas científicas e incluso literarias no imbuidas en la visión occidental, blanca y de clase media (Esteban 2013, 249).

- En otras palabras, a pesar de la apertura, se mantiene la posibilidad para que medien estereotipos corporales y formas de gestión del cuerpo predeterminadas, que es interesante evidenciar y resignificar, y esto sucede en muchas de las clases. No obstante, en otros instantes, dentro del trabajo corporal y artístico, los niños y las niñas descubren y viven la experiencia de que no solamente son seres pensan- 
tes, sino que son seres sensibles y expresivos y que su empoderamiento los lleva a sentirse respetados, libres y reales.

- Contribuir en la formación de seres humanos conscientes, espirituales y libres en sus decisiones debe ser el fin último de la educación. Y para esto, hay que prestar atención a las contradicciones y a los nuevos desafíos que se enfrentan cada día, abriendo las posibilidades y evitando la cristalización de conceptos y formas de hacer para crear un constante devenir.

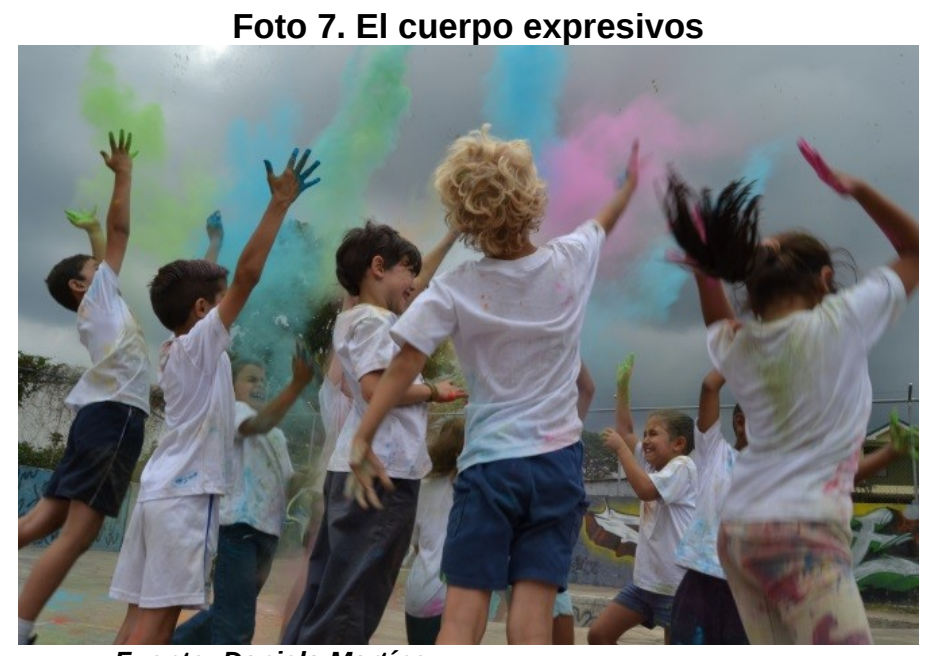

Fuente: Daniela Martínez.

\section{Bibliografía}

Araya Espinoza, Alejandra. 2006. «El Castigo físico: el cuerpo como representacón de la persona, un capitulo en la historia de la occidentalización de América». Historia, 39(2), 359-367. doi: 10.4067/S0717-71942006000200001.

Esteban, Mari-Luz. 2013. Antropología del Cuerpo: Género, itinerarios corporales, identidad y cambio. Segunda edición. Barcelona: Edicions Bellaterra. Acceso el 1 de marzo del 2017. https://drive.google.com/file/d/OBw3yPOp2B3dT2hnbmdTQ05ieVE/view?pli=1

Hurtado, Deibar René. 2008. «Corporeidad y Motricidad. Una forma de mirar los saberes del cuerpo». Revista Educación y Sociedad, 29(102) 
Acceso el 3 de febrero 2017. http://www.scielo.br/scielo.php? script=sci_arttext\&pid=S0101-73302008000100007.

Le Breton, David. 2012. Antropología del Cuerpo y Modernidad. Buenos Aires: Nueva Visión.

Lengborn, Thorbjörn. 2001. «Ellen Key (1849-1926)"». Perspectivas, 3(3-4):

873-886. Acceso: el 5 de junio 2017. http://www.ibe.unesco.org/sites/default/files/keys.pdf

López Quintáz, Alfonso. 2006. Enseñanza Escolar y Formación Humana: la conversión de profesores en formadores. Buenos Aires, Argentina: Puerto de Palos, S. A.

Lowenfeld, Viktor. 1973. El niño y su arte. Buenos Aires, Argentina: Editorial Kapelusz S.A., octava edición.

Masón, Laurencia. 2014. «El cuerpo como espacio de disidencia». Periódico diagonal. Acceso el 15 de febrero del 2017. https://www.diagonalperiodico.net/cuerpo/22353-cuerpo-como-espaciodisidencia.html

Montessori, María. 1982. El niño, el secreto de la infancia. México D.F: Editorial Diana.

Montessori, María. 1986. Formación del hombre. México D.F.: Editorial Diana. Mora, Ana Sabrina. 2010. «Propuestas metodológicas en investigaciones socio-antropológicas sobre el cuerpo». Blog del Grupo de Estudio del Cuerpo, La Plata. Acceso el 15 de marzo del 2017. http://grupodeestudiosobrecuerpo.blogspot.com.ar/2010/06/propuestasmetodologicas-en.htm

Pateti, Yesenia. 2007. «Reflexiones Acerca De La Corporeidad En La Escuela: Hacia La Despedagogización Del Cuerpo». Revista PARADIGMA, 28(1). Acceso el 12 de marzo. http://revistas.upel.edu.ve/index.php/paradigma/article/download/1715/7 24. 
Penchasky, Mónica. 2009. Sinvergüenzas: la expresión corporal y la infancia. Buenos Aires: Lugar Editorial.

Pineau, Pablo, Ines Dussel y Marcelo Carusso. 2013. La escuela como máquina de educar. Primera edición, Quinta reimpresión. Buenos Aires, Argentina: Paidós.

Puiggrós, Adriana. 2016. La educación popular en América Latina: Orígenes, polémicas y perspectivas. Buenos Aires, Argentina: Edicciones COLIHUE.

Vallejo, Joaquín Benito. 2001. Cuerpo en armonía: leyes naturales del movimiento. Barcelona, España: INDE Publicaciones. 